\title{
Agility in Information Systems: Enabling Capabilities for the IT Function
}

\author{
George Hobbs \\ Department of Information Systems \\ The University of Melbourne, Australia \\ georgehobbs@gmail.com \\ Rens Scheepers \\ Department of Information Systems \\ The University of Melbourne, Australia \\ r.scheepers@unimelb.edu.au
}

\begin{abstract}
This research identifies how the IT function can create agility in existing information systems. Agility is the capability to quickly sense and respond to environmental perturbations. We contrasted perspectives on agility from a widely used industry framework and that of the IS research literature. Beer's Viable System Model was a useful meta-level theory to house agility elements from IS research and it introduced cybernetic principles to identify the processes required of the IT function. Indeed, our surveys of 70 organizations confirmed that the applied theory better correlates with reported agility than does existing industry best practice.

The research conducted two quantitative surveys to test the applied theory. The first survey mailed a Likert-type questionnaire to the clients of an Australian IT consultancy. The second survey invited international members of professional interest groups to complete a web-based questionnaire. The responses from the surveys were analyzed using partial-least-squares modeling. The data analysis positively correlated the maturity of IT function processes prescribed by the VSM and the likelihood of agility in existing information systems. We claim our findings generalize to other large organizations in OECD member countries.

The research offers an agility-capability model of the IT function to explain and predict agility in existing information systems. A further contribution is to improve industry 'best practice' frameworks by prescribing processes of the IT function to develop in maturity.
\end{abstract}

Keywords: IT function, Agility, Viable system model. 


\section{Introduction}

This research extends the theory on agility in information systems. Agility has been described as the capability to effectively sense and respond to environmental change (Newman and Logan, 2006a). Much of the current IS literature focuses on questions relating to what agility is and if information systems enable agility in the enterprise. This research takes up the unaddressed question of how the IT function of large organizations can enable agility. In doing so, this research extends the theoretical perspective to practice by offering a tested model that is prescriptive for the IT function.

Agility in information systems is a topic of recent interest to IS academics and practitioners (Sambamurthy et al., 2007, Seo and La Paz, 2008, Weill et al., 2002). Our literature review of IS journals evidenced an emerging research interest in agility since 1998. Luftman and McLean's (2004) survey of the Society of Information Management had agility ranked fifth amongst 22 concerns.

This research found that information systems agility is also a topic of interest amongst the highest levels of corporate management. We conducted a survey of business and IT managers in 70 companies that asked the highest level in their organizations that had discussed agility in information systems. This 2008 survey found that the Chief Executive Office had discussed agility in $31.65 \%$ of cases, followed by corporate-level IT executives (25.32\%) and corporate-level business executives (15.19\%). A minority of respondents reported agility being discussed at a highest level beneath that of corporate-level offices: mostly amongst IT executives and a business group $(10.13 \%)$, and business unit leaders $(8.86 \%)$. The survey confirmed the interest in information systems agility amongst corporate level executives of large organizations.

Both IS practice and research appear to be converging on a common concept of agility. The concept consists of recognition of a business environment that fluctuates quicker than conventional planning cycles, the need to sense environmental fluctuations, the need to respond using existing information systems, and organizational readiness to effect the sensing and response (Luftman and McLean, 2004). Gartner Research defines agility "as an organization's ability to sense environmental change and respond efficiently and effectively to that change" (Newman and Logan, 2006b p. 3).

The research topic explores how the IT function enables agility in existing information systems. Weill et al. (2002) offer a concise definition of information systems as IT-conducted business initiatives. This research accepted this definition with the qualification that the information systems are the result of IT investments deliberated upon by the IT function and not merely utilizing a commonplace technology.

The IT function is the personnel and their work processes that have a responsibility for the delivery of information systems. Henderson and Venkatraman (1993) recognize an internal IT domain composed of architectures providing choices of the technical infrastructure configuration, work processes to operate the technical infrastructure and skills to manage the technical infrastructure. This internal domain is within the organization and, distinct from the actual technical infrastructure, characterizes the IT function. This research focused on the IT function of large enterprises, of 250 or more employees, in economically developed countries and enterprises in all sectors.

This research extends the IS theoretical literature to pose the question:

How can the IT function enable agility in existing information systems?

The above is not to be confused with the question: Does agility in information systems enable business agility? The later is the subject of existing discussion in the IS research literature and an answer in the affirmative was an assumption of this research.

To address the research question, we developed a theory for explaining and predicting (cf. Gregor, 2006). Cybernetics provided a metalevel model for the explanative theory. Testa- 
ble hypotheses support a prediction that agility increases with the process maturity of the IT function.

To address the research question from the IS practice perspective, this research also developed a theory for design and action (cf. Gregor, 2006). This research sought to inform industry 'best practice' frameworks on structuring an IT function to enable agility in existing information systems.

\section{Literature Review}

We reviewed the current theoretical and practice perspectives on agility in information systems. First, the IS literature on agility was reviewed to derive the current theoretical perspective. Second, we derived from the best practice frameworks the current practice perspective for the IT function to action agility. We identified the gaps between theoretical and practice perspectives on agility.

\section{Theoretical perspectives on IS agility}

IS researchers discuss a new era where a firm's performance depends on the IS capability to effect agility and less on identifying strategic IT investments (Desouza, 2006, Mathiassen and Pries-Heje, 2006, Overby et al., 2006, Peppard and Ward, 2004, Sambamurthy et al., 2003, Weill et al., 2002). Our review indicated an emerging IS research interest in agility over the past ten years, with a special edition of the European Journal of Information Systems (volume 15 issue 2) causing a publication spike in 2006.

Many authors have linked IT with enterprise agility. Agarwal and Sambamurthy (2002) discuss a number of organizational structures for the IT function observed in agile enterprises. Agarwal and Sambamurthy emphasize drawing IT managerial responsibilities into alignment with core business units, as appropriate for the role of IT in a particular firm, and an analysis that IT now plays a more prominent role in corporate agility. Weill et al. (2002) defines agility as a set of business initiatives an organization can readily implement. While making no claims of causality, their paper finds significant correlation between strategic agility and IT-infrastructure capability.
Sambamurthy et al. (2003) suggest firms assess their IT investments and capabilities in terms of their quality to generate digital options for IT-enabled business process and knowledge management initiatives. The implication is that digital options enables agility in information systems by responding to an opportunity in less time than making a full IT investment at the time of the opportunity's arrival. The cost of the anticipated opportunity failing to arrive is forgoing the initial IT investment in the digital option. A goal of a portfolio of digital options is that the value of opportunities captured from those options that 'strike' outweighs the other options that are 'out of the money'.

Peppard and Ward (2004) discuss a new era of information systems where an organization's performance significantly depends on an IS capability to effect agility and is less dependent on identifying strategic IT investments. This IS capability can be portrayed as having three inter-related competencies. First, are the 'exploitation' competencies of the IT function arising from the fusion of business knowledge and IS knowledge. The second competencies are the reusable IT infrastructure. The last competencies of an IS capability for agility is an effective use process. This is a process of the IT function monitoring and improving the value realized from the existing information systems.

Lyytinen and Rose (2006) propose early exploration and late exploitation capabilities as central for an agility model. First, sensing fluctuations in the business environment requires an early exploration capability and has process goals that allow high speed, risk and start-up costs. Second, the late exploitation capability to adapt existing information systems has process goals to reduce cost and risk and to increase quality.

Overby et al. (2006) recognize agile firms as continually sensing opportunities for competitive action in their environment and marshal their assets to seize opportunities. Overby et al. further supports the concept of digital options and classifies types of options for busi ness process and knowledge management 


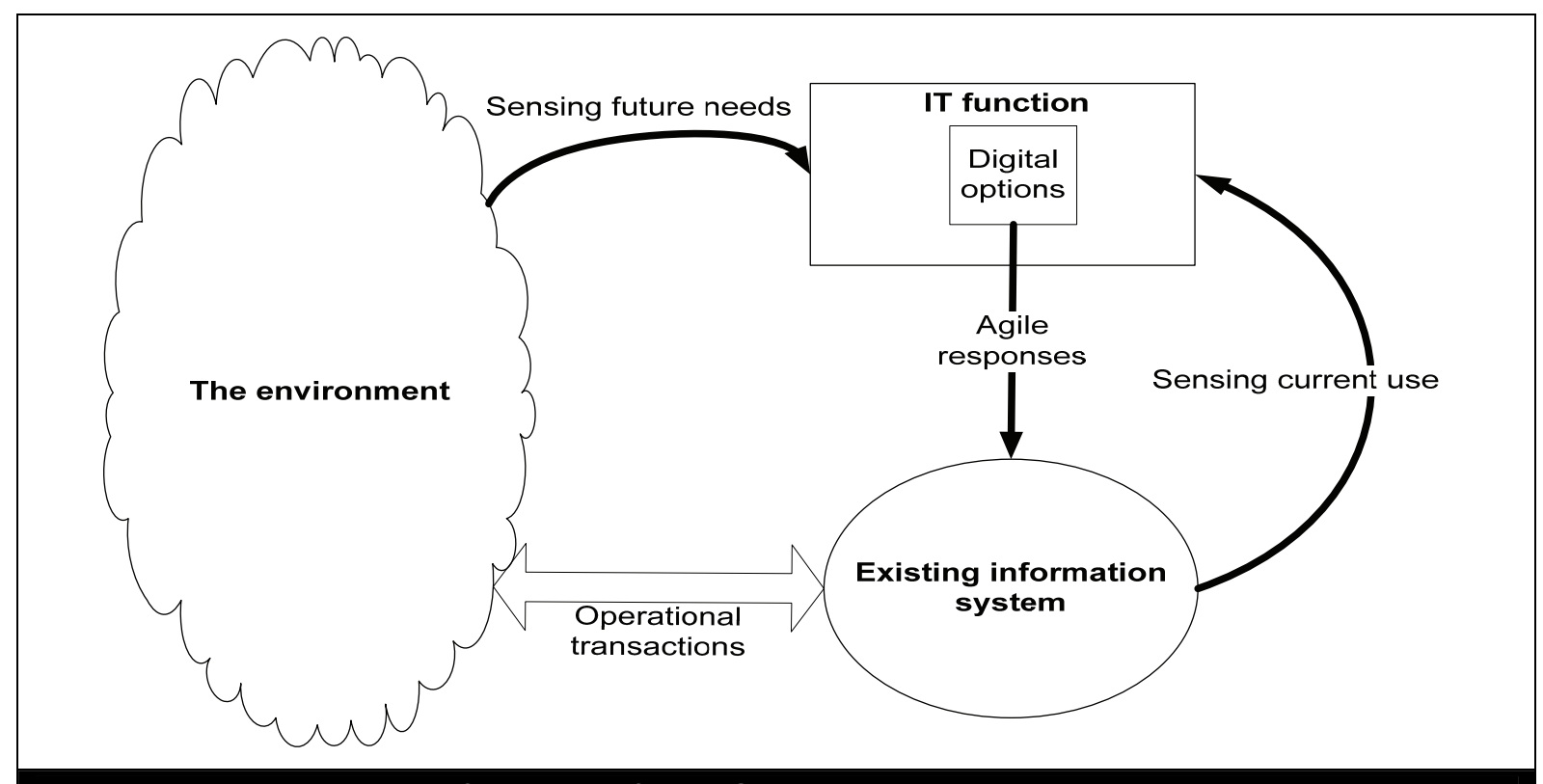

\section{Figure 1 - A basic model for agility from IS theory}

initiatives.

Goethals et al. (2006) give an overview of how organizations can create enterprise architectures. A justification for enterprise architectures is that the availability of architectural descriptions enhances agility. Goethals et al. justification for enterprise architectures is a retelling of the Law of Requisite Variety in the context of the IT function, namely a model can be less complex than the operating process, but must be of requisite variety to control the process (Conant and Ashby, 1970).

Fink and Neumann (2007) found empirical support for the proposition that existing information systems must be managed by the IT function for agility. They tested the hypotheses that IT personnel capabilities positively affect IT infrastructure capability and that IT infrastructure capability positively affect ITdependent organizational agility outcomes. A web-based survey collected data from IT managers across a range of industries. Fink and Neumann (2007) is an instance of presenting an IS theory for predicting agility without a theoretical explanation (2006). The paper leaves explanatory mechanisms of how IT personnel and IT infrastructure capabilities afford agility for future research.
Our review of IS theoretical literature on agility only found Sambamurthy et al. (2007) as an instance of a paper with a theory for explaining and predicting. The distinguishable attributes of the theory type is that it provides predictions and has both testable propositions and causal explanations (Gregor, 2006). However, Sambamurthy et al. (2007) has limited the internal validity due to its measurement model. The independent variables of IT and operational capabilities have only one or two measurement items, and the dependent variables of organizational benefits have one reflective measure item each.

Four elements of agility can be discerned from the IS literature, which become a basic model for agility (Figure 1). In Table 1 we map these elements to sources from the IS literature review on agility and to theory types defined Gregor (2006).

First, the IT function's fuses business and technical knowledge to sense directly the business environment to forecast opportunities and threats that might present in the future. The second element is sensing the current use of existing information systems, which indirectly senses the fluctuations in the environment and uncovers future trends. Mostly the analyzing and explaining theories (Gregor 2006) support both these elements. 


\begin{tabular}{|c|l|l|}
\hline \multicolumn{2}{|c|}{ Table 1 - Concept matrix for agility from IS theory } \\
\hline Agility concept & \multicolumn{1}{|c|}{ Article } & \multicolumn{1}{c|}{ IS Theory type } \\
\hline \multirow{5}{*}{ Sensing future needs } & Desouza (2006) & Analyzing \\
& Lyytinen and Rose (2006) & Analyzing \\
& Overby et al. (2006) & Explaining \\
& Patten et al. (2005) & Analyzing \\
& Sambamurthy et al. (2003) & Explaining \\
& Seo and La Paz (2008) & Design and Action \\
& Seo et al. (2006) & Explaining \\
\hline \multirow{5}{*}{ Digital options } & Cornford et al. (2007) & Explaining \\
& Goethals et al. (2006) & Design and Action \\
& Sambamurthy et al. (2003) & Explaining \\
& Seo et al. (2006) & Explaining \\
& Overby et al. (2006) & Explaining \\
& Weill et al. (2002) & Analyzing \\
\hline \multirow{5}{*}{ Sensing current use } & Galliers (2006) & Explaining \\
& Lyytinen and Rose (2006) & Analyzing \\
& Peppard and Ward (2004) & Analyzing \\
& Sambamurthy et al. (2003) & Explaining \\
& Seo and La Paz (2008) & Design and Action \\
\hline \multirow{5}{*}{ Agile responses } & Andrade and Fladeiro (2002) & Design and Action \\
& Börjesson et al. (2006) & Design and Action \\
& Fitzgerald et al.(2006) & Design and Action \\
& Holmqvist and Pessi (2006) & Design and Action \\
& Seo and La Paz (2008) & Design and Action \\
& Seo et al. (2006) & Explaining \\
& Umar (2005) & Zesign and Action \\
& Zhao et al. (2007) & Design and Action \\
\hline
\end{tabular}

There is little support for these two elements by the theories of design and action, with the exception of Seo and La Paz (2008) stressing the personality traits and skills of IT managers for sensing and agility.

Third is generating digital options for forecasted needs. This element includes constructing a portfolio of digital options, which makes initial IT investment for each digital option and decides to exercise a digital option into a full IT investment once a forecasted opportunity arrives. The elements are heavily influenced by Sambamurthy et al. (2003), which is seminal for other reviewed papers (Berente, 2005, Raschke and David, 2005, Sambamurthy et al., 2007). There are few theoretical contributions for the digital options competency with the design and action theories.

After deciding to exercise a digital option, the last element is adapting the existing information systems to complete the agile response. IS design and action theories (Gregor, 2006) dominate this element. The most of these contributions in IS literature focus on how the IT function addresses particular agile software methods.

This review of the IS research on agility revealed a profile of the types of IS theory published and distilled a basic model of agility in information systems. Notably, there are no theories for explaining and predicting (cf. Gregor, 2006) the basic model of agility in information systems. The precursor theories for analyzing and explaining exist, but a theory for explaining and predicting is yet to emerge. Under represented in the IS literature are theories for design and action concerned with sensing future needs from the business environment or building a portfolio of digital options.

\section{Practice perspectives on IS agility}

The practice perspective on how the IT function can enable agility was deduced from a claimed 'best practice' framework. The Control Objectives for Information and related 
Technologies (COBIT) is arguably the most appropriate control framework available to align information systems and business goals, and is increasingly being used by a diverse range of organizations throughout the world (Ridley et al., 2004). COBIT represents the consensus of experts (IT Governance Institute, 2007) and from this control framework this research deduced the dominant design and action theory (Gregor, 2006) for agility from the IS practitioner perspective.

Within the COBIT framework is a goal of Create IT agility (IT Goal 5), which links four measurable control objectives (see Table 7). COBIT defines agility as responding to changing business requirements from the customer perspective and managing business change from an internal perspective. This definition reflects COBIT dependence on received business requirements and strategy (IT Governance Institute, 2007). A theory to design and action agility is explicit in the COBIT framework control objectives linked to the goal.

Comparing the IS theoretical perspective on agility with the IS practice perspective has highlighted four gaps. First, the COBIT definition of agility is narrower than the IS theoretical perspective, as it based on the IT function responding to received business requirements and strategy. The IS theoretical perspective observes that deliberate alignment of information systems with a stated business strategy has had limited success (Galliers, 2006). The IS theoretical perspective on agility has information systems being subject to less long-term planning strategies and more to constant adaptation (Desouza, 2006, Peppard and Ward, 2004). The COBIT definition of agility is also narrower than other IS practice perspectives (Luftman and McLean, 2004, Newman and Logan, 2006b), which include the IT function sensing and responding directly with the business environment.

The second gap was the capability for the IT function to sense future needs directly from the environment. The IS theoretical perspective emphasizes this forecasting capability (Desouza, 2006, Overby et al., 2006, Sam- bamurthy et al., 2003). In the IS practice perspective, the capability to sense environmental change is noted by Gartner (Newman and Logan, 2006b), but the COBIT goal of Create IT agility is not linked to any process for this capability. The COBIT concept of agility being a response to a received business strategy is the likely cause of it not addressing the IT function directly sensing future needs from the environment.

The third gap between the IS perspectives was concerned with maintaining digital options that can be readily implemented. This element is put forward in the IS research literature on agility (Overby et al., 2006, Sambamurthy et al., 2003, Weill et al., 2002). From the IS practice perspective, the theory of design and action deduced from the enabling factors for the COBIT goal to Create IT agility is silent on this capability.

Last, the IT function sensing current use of the information systems was not included in the IS practice perspective on agility. There are several references to this capability in IS theoretical literature which discuss systemic insight (Sambamurthy et al., 2003), effective use processes (Peppard and Ward, 2004) and the assessment of unexpected consequences that were experienced in existing activity (Galliers, 2006). The IS practice perspective is silent on this capability, as deduced from the stated COBIT enablers to Create IT agility.

\section{Theory development}

This research assumes that enterprise agility and information system agility exist and that information system agility enables enterprise agility. This research also assumes that the IT function enables information systems agility. From these assumptions, the theoretical departure made by this research was explaining and predicting how the IT function enables agility in existing information systems. In other words, this research claims unearthing a theoretical mechanism for the IT function to enable agility. From this departure point in the IS theoretical perspective, this research informs IS practice perspective by 
prescribing how the IT function can enable agility.

The theory development drew parallels between the IS research into agility in information systems and an established model of cybernetics. A cybernetic model was a valid method for a number of reasons. First, the business issue of agility for sensing and responding to the environment (Overby et al., 2006) is the fundamental problem addressed by cybernetics (Ashby, 1956, Beer, 1984). Agility in information systems requires alertness by IT personnel to perceive incoming signals from its internal and external environments, processing the signals and responding adequately. In the research context, the signals might include business exceptions or new technology reports. The processing of income signals require filtering accurate information to drive decision-making for response in a timely way. The challenge for the IT function is processing an overwhelming collection of signals, in un-standardized formats, and from overlapping sources, which overloads decision-makers (2008). This signal overload problem of is must be addressed for agility, and is the problem addressed in the cybernetic models to comply with the law of requisite variety (Ashby, 1956, Conant and Ashby, 1970). The law of requisite variety recognizes that environment inherently contains more variety than the system's processes can absorb and therefore demands that the system must attenuates environmental variety to what is requisite to control the system's processes.

Second, enabling agility in information systems appears subject to the cybernetic theorem that every good controller of a system's processes must be a model of that system. The controller of a system cannot know all the details of the system's processes and must have variety attenuated to deliver the requisite amount of information to manage the system. Theoretical perspectives on agility of information systems require a requisite knowledge base to manage information received from the environment and to enable adaptations of existing IT and work processes (Desouza, 2006). This concept is consistent with the cybernetic theorem of managing environmental perturbations by maintaining a model of operations. The model can be less complex than the operating process but must be of requisite variety to control the process (Conant and Ashby, 1970). This second point is distinct from the first made in this section, which was concerned with the requisite variety in the process, while the current point is concerned with the requisite variety in the model of the process controller.

Last, elements from the basic model of agility from IS theory (Figure 1) can be understood with the cybernetic theory of the Viable System Model (VSM) (Beer, 1979, 1984). Two of these elements are externally focused future planning, and an internally focused effective use process (Desouza, 2006, Galliers, 2006, Peppard and Ward, 2004). These elements can be interpreted as subsystems of the VSM and the model's known dynamic between these subsystems informs an understanding of the basic model of IS agility.

The validity of a cybernetic framework for an explaining and predicting theory is supported by Gregor (2006). Gregor states a commonality of cybernetics with general system theory, which provides a high-level way of thinking about IT systems. Systems are in a continuous state of exchange with their environment and other systems, and modeled with concepts of input, throughput, output, feedback, boundary and environment. Gregor suggests general systems theory and cybernetics as examples of 'grand theories' for explaining and predicting.

\section{The viable system model}

The following description of the VSM is mostly derived from Beer's The Heart of Enterprise (Beer, 1979). The viable system model is a generalized description of any system capable of self-adaptation in a fluctuating environment. Viability is maintaining a separate existence and identity from other systems that share the environment. To be selfadapting, a viable system has subsystems that perform operations that define the system's identity, and subsystems that adapt those operations to achieve viability. The 
Agility in Information Systems: Enabling Capabilities for the IT Function / Hobbs \& Scheepers

VSM views an organization as an information processing system striving to maintain balance when faced with perturbations from the environment. The concept of recursion is essential for the VSM to encompass complex organizations, as any viable system contains operational subsystems that are themselves viable systems, and can be diagnosed at the lower level of recursion.

Figure 2 is a general representation of the VSM without adaptation to the research topic. System ONE to System FIVE denotes the subsystems of the VSM. For simplicity, the figure does not show the interactions between the three sub-systems within the metasystem and those between the sub-systems within the operations of the viable system. The figure does show interactions that between the meta-system, the operations and the environment of the viable system.
System ONE occurs in many instances in a viable system and each instance is an independent operation, with their coordinated behaviour composing the identity of the viable system. An intersection of the operational requirements and coherence imposed by the meta-system of the viable system affects the freedom of any System ONE instance. The instances of System ONE can be recognized as the core business systems that transact with the outside environment, e.g. with customers, suppliers, business partners and regulators.

Instances of System ONE are subject to a resource bargain within the organization. This is an exchange to provide resources for System ONE for performing in a preferred manner. System ONE has rules of behavior that it must observe, e.g. legal obligations and corporate rules. Figure 2 shows three instances

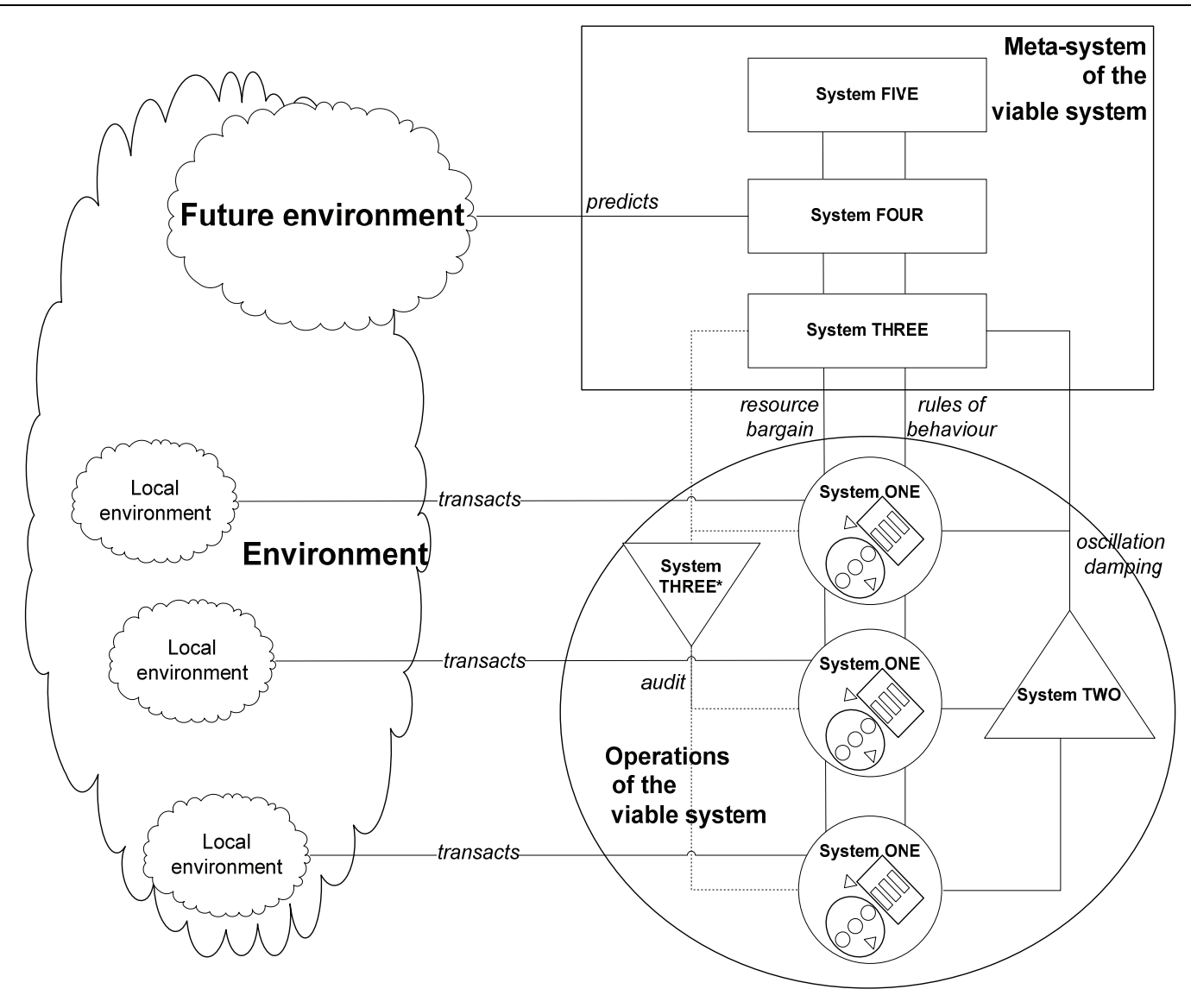

Figure 2 - The Viable System Model 
of System ONE and each instance shows an imbedded VSM at the lower level of recursion.

The function of System TWO is to damp oscillations that will arise between both the meta-system and System ONE and amongst other instances of System ONE at the same level of recursion. System TWO is recognizable by the attributes of a network of elements for stabilizing the execution of System ONE instances within homeostatic levels, providing a service to a System THREE to dampen unexpected fluctuations from the System ONE instances, and transduction of code-sets to relay information across the boundaries of System ONE instances.

System THREE is responsible for the inside and now control of System ONE. The tasks that recognize System THREE are sourcing for the plans, programs and schedules to adapt System ONE; monitoring the behaviour of System ONE resulting from the regulatory action of System TWO; and monitoring System TWO.

System THREE has a helper task of System THREE* ${ }^{*}$ which is responsibility to sporadically audit System ONE. System THREE* is not logically separate from System THREE, but normally operates physically apart from System THREE. The attributes that recognize System THREE* are ensuring that directions coming to System ONE from System TWO are being performed as reported to System THREE, filling any time gaps in reporting, and making special assessments of System ONE.

System ONE, System TWO and System THREE have concentrated on the internal aspects of stabilizing the system. The system has no mechanism for planning or adapting: this is the role of System FOUR. System FOUR spends most of its time looking outside the system and to the future. System FOUR is necessary for the viable system to anticipates change and adjust System ONE to fit a dynamic environment. This is accomplished by possession of a model of the viable system and its environment and is consistent with the Conant-Ashby Theorem (Conant and Ashby, 1970) that every good regulator must have a model of the system it is regulating.
System FOUR gathers data from the environment and collects and stores data on the state of System ONE (obtained via System THREE). Based on this data, System FOUR can build probabilistic models for use in forecasting events that may occur in the environment and predict how System ONE will react to those events. System FOUR indicates structural changes required that lead to a different configuration of System ONE instances and System TWO.

System FIVE sets the overall goals of the system and constrains the possibilities of adaptive behaviour provided when System FOUR couples with System THREE. System FIVE produces policy that governs the behaviour of the total system i.e. top-level rules. System FIVE monitors the System THREE and System FOUR couple, supervises their behaviour and mediates conflicts. System FIVE thinks about what the system produces and why. Finally, System FIVE absorbs any variety that is not disposed of by the System ONE, System TWO, System THREE and System FOUR.

In the recursive nature of the VSM, each instance of a System ONE in a viable system in-focus is itself a viable system in the next level of recursion down. Collectively, Systems THREE, FOUR and FIVE are the metasystem for the control of a viable system, but not viable systems themselves. The metasystem does not exist for itself, but is a necessary redundancy to regulate the complexity in the environment that embeds the viable system.

Recent VSM applications include small cooperatives (Walker, 2001), the UK electricity market (Shaw et al., 2004), the Australian Taxation Office (Haslett and Sarah, 2006) and several case studies of the St Gallen Institute of Management (Schwaninger, 2006). This research used the terms Applications, Integration, Control, Intelligence and Policy to respectively describe System ONE to System FIVE, for an IS research audience. An adoption of localized names for the subsystems is a liberty often taken by interpreters of the VSM. 


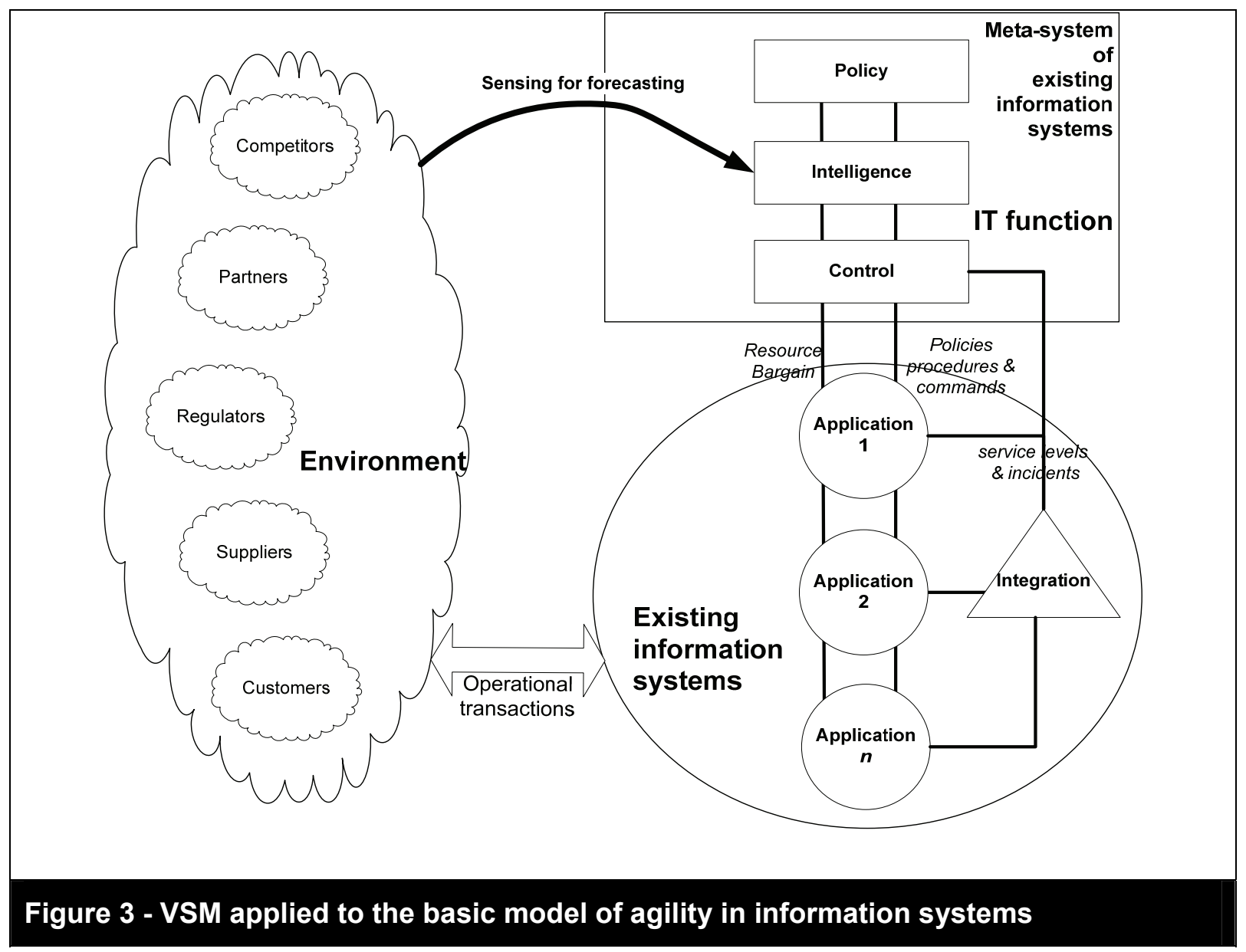

Figure 3 depicts applying the VSM to the IT function. The viable system is composed of the existing information systems (circled) which produce the identity of the viable system, and the IT function (boxed) as the metasystem of the information systems.

The VSM subsystems of System ONE are interpretable as the Applications of the information systems. These are instantiations of electronic processes and networks used to enable business initiatives and the business users of those initiatives. The instantiations of the IT can be a portfolio of ERP packages or legacy systems. Applications receive sustaining resources from the organization in return for performing at prescribed service levels, within the legal obligations and corporate rules.

System TWO is interpretable as the Integration between the Applications of the informa- tion systems. This can be instantiations of system integration software to stabilize applications and the transduction of code-sets. Examples of the integration software include Data Warehousing and Enterprise Applications Integration (Markus, 2000). IT support groups are often involved to dampen fluctuations between Applications not handled electronically by the system integration software, i.e. though exception/error-handing work procedures. Applications and Integration compose the information system, which is subject to the meta-system of the IT function.

The System THREE, System FOUR and System FIVE meta-system of the information systems is the IT function. System THREE is interpretable as the Control component of the IT function. Control is often the accountability of the Application Management Office, which includes a disciplined approach to delivering 
IT-enabled business initiatives beyond the usual view of project completion, a single point of ownership for application support and a single point of contact for operational support. The System THREE* can be seen as the Audit component of the IT function, such as COBIT high-level processes of monitoring and evaluating (IT Governance Institute, 2007).

System FOUR is interpretable as the Intelligence component of the IT function. In many organizations, this is the accountability of the Strategy and Enterprise Architecture office. Deliverables of the office include identified IT trends and opportunities, approved current and target enterprise architectures, and transition roadmaps. The System FOUR attribute of building probabilistic models to forecast events and how System ONE will react to those events is consistent with discussion of the IS agility as a family of future electronically-enabled business initiatives that are readily implemented (Weill et al., 2002), and digital options (Sambamurthy et al., 2003).

System FIVE is interpretable as the Policy component of the IT function. In many enterprises, this role is that of a steering committee, with representation by the IT function. The IT governance model specifying decision rights and accountabilities for important IT decisions configures the Policy component. The aim is to encourage desirable behaviors in the use of IT. Weill (2004) conducted an international survey of more than 250 organizations and found a wide variety of IT governance arrangements for decision rights. These decision rights included high-level statements about business uses, policies and rules of IT; and IT project approvals and justification techniques. These decision rights of the surveyed IT governance arrangements are consistent with the System FIVE attributes found in Beer (1979).

The VSM provides a theory for explaining and predicting for the basic model of agility (Figure 1), which is lacking in the IS research literature. The lack of a theory for design and action to sense future needs (Desouza, 2006, Otto et al., 2007, Overby et al., 2006, Sam- bamurthy et al., 2003) and to build a portfolio of digital options (Overby et al., 2006, Sambamurthy et al., 2003, Weill et al., 2002) is addressed by the prescribed attributes of the VSM meta-system.

\section{Hypothesis development}

The theory development of this research proposed the applying the VSM meta-system to the IT function and interpreted the subsystems of the meta-system as the components of the IT function. We represented the meta-system as the independent variable of POLINTCON of our primary hypothesis.

H1. The more mature the coupled processes of Policy, Intelligence and Control of the IT function (POLINTCON), the more often digital-options for the existing information systems are exercisable (D-OPTIONS).

In itself, POLINTCON is a composite of the Policy, Intelligence and Control components of the IT function. As a composite, POLINTCON possesses a mutual property to enable agility in existing information systems. In applying the VSM, the Policy, Intelligence and Control components individually do not possess this property. POLINTCON possesses the mutual property only by relating the components.

The dependent variable of hypothesis $\mathrm{H} 1$ relates to digital options. As recalled from the literature review, digital options is an existing concept of IS theorists and defined as rights to future IT investment choices without a current obligation for full investment made by an initial IT investment (Sambamurthy et al., 2003). In this research, exercise refers to making a full IT investment at the time of the opportunity's arrival. The opportunity was previously forecasted after sensing the business environment and this forecasting resulted in an initial IT investment to create the digital option. The initial IT investment for the forecasted opportunity might range from adapting an existing information system to be readily configurable to respond, creating a detailed design, creating a high-level design, 
to formulating an alternative IT architecture for a new business model.

If the forecasted opportunity arrives, the digital option is exercisable, in that a decision is required for a full IT investment. Typically, a steering committee makes the decision to exercise a digital option based on resources required, top-level policies and the integrity of the information systems (cf. Beer, 1979). The decision to act on an exercisable digital option is that of Policy, when applying the VSM meta-system to the IT function. In the context of adapting existing information systems, an exercised digital option becomes the agile response for forecasted fluctuations in the environment.

The response is agile when it is made in less time than conventional planning cycles (Luftman and McLean, 2004). In conventional planning, the full IT investment for a response commences on or after the arrival of a business opportunity. Where there is an organizational readiness to affect agility, the initial IT investment of the exercised digital option reduces the response time required, when calculated from the arrival time of the opportunity. The initial IT investment is foregone if the opportunity fails to arrive, or if the opportunity arrives and a decision is made not to exercise a digital option.

The dependent variable in hypothesis $\mathrm{H} 1$ refers to the frequency of exercisable digital options, in preference to exercised digital options. The frequency of exercisable digital options was one measure of agility in information systems available to this research. Later agility activity measures are the frequency of exercised digital options or the frequency of agile responses implemented. The research measured the earlier activity to minimize the later confounding factors in the decision to exercise and implement a digital option, particularly budgetary considerations to make a full IT investment.

POLINTCON and D-OPTIONS are ontologically different. POLINTCON is a structure of rules and non-human resources persistent in time. In contrast, D-OPTIONS are a sporadic activity of human agency enabled by PO-
LINTCON. Exercising digital options is a necessary activity for agile responses to adapt existing information systems. Applying the VSM to the IT function, in the context of the basic model of the IS theoretical perspective of agility suggested the causal relationship between POLINTCON and D-OPTIONS.

The hypothesis $\mathrm{H} 1$ is at the level of analysis of the IT function as a meta-system of the existing information systems, as interpreted from the VSM. This meta-system is an amalgam of System FIVE, System FOUR and System THREE. This informs a more granular level of analysis within the IT function of a Policy, Intelligence and Control structure. This analysis allows the unbundling of the primary hypothesis into three lower level hypotheses:

H1a. The more mature the processes of Policy of the IT function (POLICY), as a part of POLINTCON, the more often digital-options for the existing information systems are exercisable (DOPTIONS).

H1b. The more mature the processes of Intelligence of the IT function (INTELL), as a part of POLINTCON, the more often digital-options for the existing information systems are exercisable (DOPTIONS).

H1c. The more mature the processes of Control of the IT function (CONTRL), as a part of POLINTCON, the more often digital-options for the existing information systems are exercisable (DOPTIONS).

Hypotheses $\mathrm{H} 1 \mathrm{a}, \mathrm{H} 1 \mathrm{~b}$ and $\mathrm{H} 1 \mathrm{c}$ are not an alternative to $\mathrm{H} 1$, but at a lower level of analysis. Wetzal et al (2009) discuss the utility of a two-tier hierarchical construct like POLINTCON. First, a hierarchical construct affords theoretical parsimony and reduces structural model complexity. Second, hierarchical construct models allow matching the level of analysis of the independent and dependent variables. In this research, POLINTCON is at the level of whole IT function and not the offices within the IT function where POLICY, 
INTELL and CONTRL lie. Typically, Policy lies in the steering committees of the IT function, Intelligence in the Strategic \& Enterprise Architecture office, and Control in the Application Management Offices. The level of analysis of POLINTCON matches the whole of IT function level of D-OPTIONS.

This research assumed that information system enables the enterprise agility. This assumption is based on the existing IS literature (Agarwal and Sambamurthy, 2002, Desouza, 2006, Weill et al., 2002) and was tested by the secondary hypothesis of this research.

H2. The more often digital-options for the existing information systems are exercisable (D-OPTIONS), the more likely that IT-dependent strategic benefits (ITBENEFIT) occur.

In summary, the hypotheses consists of a primary hypothesis $(\mathrm{H} 1)$ informed by the theoretical development of this research; an unbundling of the primary hypothesis $(\mathrm{H} 1 \mathrm{a}$, $\mathrm{H} 1 \mathrm{~b}$ and $\mathrm{H} 1 \mathrm{c}$ ) also informed by the same theoretical development; and a secondary hypothesis $(\mathrm{H} 2)$ informed by the IS literature. The primary hypothesis $(\mathrm{H} 1)$ tests the enabling of IS agility and the secondary hypothesis $(\mathrm{H} 2)$ tests the benefits from IS agility.

\section{Construct measurement}

The measurement of the variables of the hypotheses was by a Likert-type questionnaire. The research instrument is available in Hobbs (2010). This paper references each measurement item in the questionnaire with a two-part code. The prefix indicates the Likert scale of the item: a 'MAT' prefix indicates a six-point maturity scale, 'AGR' a five-point agreement scale and 'FRQ' a five-point frequency scale. The suffix is the question number on the questionnaire.

The measures for POLICY, INTELL and CONTRL used an ordinal scale of nonexistent, initial, repeatable, defined, managed and optimized. The maturity scale is recognizable to many IT practitioners from the 'best practice' frameworks of COBIT (IT Governance Institute, 2007) and originated from the maturity framework developed by the Soft- ware Engineering Institute at Carnegie Mellon (Humphrey, 1987). The use of maturity levels as a scale for quantitative measures has precedents in IS research (Sledgianowski et al., 2006).

The variable POLICY represented the Policy construct of the IT function. From the theoretical development of this research, this construct is an interpretation of the VSM subsystem of System FIVE. The measures for POLICY are:

- to develop and maintain a set of policies to support IT strategy. This includes policy intent, roles and responsibilities (MAT37);

- to establish and maintain an optimal coordination, communication and liaison structure within the IT function (MAT38); and

- to create a strategic plan that defines how IT goals will contribute to the company's strategic objectives (MAT39).

The measures interpret the VSM attributes of System FIVE. System FIVE produces policy that governs the behaviour of the total system i.e. top-level rules (MAT37), monitors the System THREE and System FOUR couple, supervises their behaviour and mediates conflicts (MAT38), and thinks about what is being produced and why, i.e. the viable system is produced by System ONE (MAT39) (Beer, 1979).

The three measures (MAT37, MAT38 and MAT39) reuse existing COBIT control objectives. The COBIT control objectives respectively are PO6.3 IT Policies Management, P04.15 Define the IT Relationship and P01.4 Define a strategic IT plan (IT Governance Institute, 2007).

The variable INTELL represented the Intelligence construct of the IT function. Intelligence is an interpretation of the VSM subsystem of System FOUR. The measures for INTELL are:

- to maintain a set of high-level designs for IT-enabled capabilities, which are op- 
Agility in Information Systems: Enabling Capabilities for the IT Function / Hobbs \& Scheepers

tions for forecasted business initiatives (MAT34);

- $\quad$ to implement a set of IT-enabled capabilities, which are readily configurable for forecasted business initiatives (MAT35);

- to assess any unexpected operational consequences, arising from existing information systems, to forecast business initiatives (MAT36);

- to monitor the business sector, industry, technology, infrastructure, legal \& regulatory environment trends (MAT40);

- to analyze existing and emerging technologies, and plan which technological direction to realize the IT strategy (MAT43); and

- to develop a feasibility study that examines the possibility of implementing the requirements and alternative courses of action (MAT44).

The measures interpret the VSM attributes of System FOUR. System FOUR builds probabilistic models to react to forecasted events (MAT34 and MAT36), gathers data from the environment (MAT40 and MAT43), and indicates structural changes that lead to a different configuration of System ONE and System TWO (MAT35 and MAT44) (Beer, 1979).

Three of these six measures (MAT40, MAT43 and MAT44) reuse existing COBIT control objectives. The COBIT control objectives respectively are PO3.3 Monitoring of future trends and regulations, PO3.1 Technological Direction Planning and Al1.3 Feasibility Study and Formulation of Alternative Courses of Action) (IT Governance Institute, 2007).

The variable CONTRL represented the Control construct of the IT function. This construct is an interpretation of the VSM subsystem of System THREE. The measures for CONTRL are:

- to acquire and maintain applications in line with IT strategy and IT architecture (MAT45);

- to continuously monitor specified service level performance, and report in a format that is meaningful to the stakeholders (MAT46); and

- to report service desk activity to enable management to measure service performance and to identify trends (MAT47).

The measures interpret the VSM attributes of System THREE. System THREE sources the plans, programs and schedules to adapt System ONE (MAT45); monitors the behaviour of System ONE resulting from the regulatory action of System TWO (MAT46); and monitors System TWO (MAT47) (Beer, 1979).

The three measures (MAT45, MAT46 and MAT47) reuse existing COBIT control objectives. The COBIT control objectives respectively are Al2 Acquire \& maintain application software, DS1.5 Monitoring and Reporting of Service Level Achievements and DS8.5 Reporting and Trend Analysis (IT Governance Institute, 2007).

The variable D-OPTIONS of $\mathrm{H} 1$ and $\mathrm{H} 2$ represented the construct of exercisable digital-options for the existing information systems. The reflective measures are the respondents' experience of how often their company has exercisable digital options and have an ordinal scale of very frequently, somewhat frequently, occasionally, rarely and never. The measures D-OPTIONS are:

- have existing information systems that are readily configurable for a new business initiative (FRQ07);

- have existing detailed designs for IT that can be used, partially or wholly, for a new business initiative (FRQ08);

- have existing, high-level designs for IT that can be used, partially or wholly, for a new business initiative (FRQ09); and

- have alternative target IT architectures and road maps for new business models (FRQ10).

This construct was suggested by the concept of digital options in IS literature on agility (Sambamurthy et al., 2003). The frequency of exercising digital options observed by the 
survey respondents was the operationalization of the concept.

The variable ITBENEFIT of $\mathrm{H} 2$ represented the construct of IT-dependent strategic benefits. Measures of IT-dependent strategic benefits that might arise from agility were based on Mirani and Lederer (1998), who developed an instrument to assess the strategic benefits of IS projects. Most of their measures appear in the questionnaire:

- enhance competitiveness or create strategic advantage (AGR24);

- enable the organization to catch up with competitors (AGR25);
- align well with stated organizational goals (AGR26);

- help establish useful linkages with other organizations (AGR27); and

- enable the organization to respond more quickly to change (AGR28).

\section{Survey methodology}

Three surveys tested the correlation of variables of the maturity of the IT function and the frequency of agility outcomes. The theoretical development of this research proposed causality between these variables by applying Beer's VSM to the IT function. The unit of analysis of this research was individuals in

\section{Table 2 - Proffle of survey responses}

\begin{tabular}{|c|c|c|}
\hline & ConsultCo clients & Linkedln members \\
\hline \multicolumn{3}{|l|}{ Activity of employing organization } \\
\hline Education and training & 2 & 1 \\
\hline Electricity, gas, water and waste services & 5 & \\
\hline Financial and insurance & 5 & 6 \\
\hline Information media \& telecommunications & 1 & 16 \\
\hline Manufacturing & 3 & 2 \\
\hline Mining & 2 & \\
\hline Other community, social \& personal services & 3 & \\
\hline Professional, scientific \& technical services & 2 & 5 \\
\hline Public administration and defense & 4 & 1 \\
\hline Rental, hiring and real estate services & 3 & \\
\hline Retail trade & 2 & 3 \\
\hline Transport, postal and warehousing & 1 & 1 \\
\hline unidentified & 1 & \\
\hline \multicolumn{3}{|l|}{ Number of employees } \\
\hline Average & 10,504 & 22,499 \\
\hline Standard deviation & 27,326 & 65,549 \\
\hline Large enterprises of 250 or more & 34 & 25 \\
\hline Small-medium enterprises & & 5 \\
\hline Small office/home office of less than 10 & & 4 \\
\hline \multicolumn{3}{|l|}{ Role of respondent } \\
\hline Business stakeholders & & 2 \\
\hline Business managers & 2 & 2 \\
\hline Senior business managers & 10 & 3 \\
\hline IT professionals & 1 & 10 \\
\hline IT managers & 5 & 7 \\
\hline Senior IT managers & 18 & 11 \\
\hline
\end{tabular}


Agility in Information Systems: Enabling Capabilities for the IT Function / Hobbs \& Scheepers

the IT function of organizations who completed the survey. The level of analysis was the entire IT function of organizations, as the object of the questions.

An industry partner in this research is ConsultCo, an IT consultancy active in eastern Australia. First, twelve consultants in the enterprise architecture and strategy practice of ConsultCo piloted the survey, of which eight completed the mailed questionnaire. The pilot tested the variables to determine whether the measurement items demonstrated reliability. The pilot data collected met the Cronbach's alpha benchmark of 0.7 or higher (Gefen et al., 2000).

Subsequently, a mailed survey targeted the 257 client organizations of ConsultCo. ConsultCo provided Australian mailing addresses for potential respondents, identifying an IT professional and a business stakeholder in most of the organizations. The initial mail-out was 12 September 2008, and the follow-up mail-out was 10 October 2008. Completed responses from both the initial and follow-up mailings continued to the received until 20 November 2008. Of the total 506 individuals mailed a questionnaire, 169 were returned undelivered due to insufficient addressing or the contact no longer being at the address. The undeliverable questionnaires resulted from currency issues in the ConsultCo customer database. This left a possible 204 organizations with at least one deliverable survey. Thirty-four organizations returned 36 completed surveys, giving an organizational response rate of $16.75 \%$. Table 2 profiles the responses to the mailed survey of ConsultCo clients. A workforce-hire firm and a fire ser- vice each returned two questionnaires, completed by different individuals.

The third survey was of practitioners with a subscribed interest in IT governance or control standards. The instrument of this survey was a web-based version of the questionnaire used in the mailed survey of ConsultCo clients. The web-based survey drew possible participants from four discussion groups in Linkedln.com, a professional networking website (Linkedln Corporation, 2008). We posted invitations to participate in the survey on the discussion boards of The Integration Consortium, ISACA Professionals, IT Governance and IT Governance Institute groups.

In the Linkedln survey, 66 members of the four discussion groups commenced the survey. Of these, 31 surveys were incomplete. Comments posted by respondents suggest that incompletion was due to the framing of the questionnaire for an employee of a company, whereas many discussion group members were not employees or affiliated to several companies. It cannot be assessed how many members were active in the discussion groups during the survey period of ten weeks.

Table 2 profiles the 35 completed responses to the Linkedln survey. One respondent failed to record a number of employees. The regions where the respondents mostly work were: Asia-Pacific (1); Western Europe (9); USA \& Canada (18); Greater Region of China (1); Central \& Eastern Europe (2); Latin America (2); India, Pakistan \& Sri Lanka (0); and the Middle East \& Africa (2). An assumption was that the 35 respondents represent 35 different organizations. Though the webbased survey was anonymous, the responses did not include any two organizations with a

\begin{tabular}{|l|c|c|c|c|c|}
\hline \multicolumn{1}{|c|}{ Table 3 - Summary of survey responses } & Method & Anonymity & Period & Individuals & Organizations \\
\hline Pilot of ConsultCo consultants & Mailed & No & Jun 2008 & 8 & 1 \\
\hline ConsultCo clients & Mailed & No & Sep 2008 & 36 & 34 \\
\hline $\begin{array}{l}\text { Linkedln discussion group } \\
\text { members }\end{array}$ & $\begin{array}{c}\text { Web } \\
\text { based }\end{array}$ & Yes & $\begin{array}{c}\text { Nov 2008 } \\
\text { Jan 2009 }\end{array}$ & 35 & 35 \\
\hline TOTAL & & & & 79 & 70 \\
\hline
\end{tabular}




\begin{tabular}{|l|c|c|c|}
\hline \multicolumn{1}{|c|}{ Table 4 - Construct validity and reliability } \\
\hline \multicolumn{1}{|c|}{ Variable } & AVE & Composite reliability & Cronbach's alpha \\
\hline CONTRL & 0.750 & 0.900 & 0.833 \\
\hline D-OPTIONS & 0.741 & 0.919 & 0.883 \\
\hline INTELL & 0.724 & 0.940 & 0.923 \\
\hline ITBENEFIT & 0.710 & 0.924 & 0.898 \\
\hline POLICY & 0.810 & 0.927 & 0.882 \\
\hline POLINTCON & 0.651 & 0.957 & 0.951 \\
\hline
\end{tabular}

similar region, industry sector and estimate of employees.

The ConsultCo client and Linkedln surveys appear to sample the same population. Each variable of hypotheses $\mathrm{H} 1$ and $\mathrm{H} 2$ was subject to parametric and non-parametric tests for the two independent samples of the ConsultCo client respondents and the Linkedln discussion group respondents (Table 3 ). The t-test and Mann-Whitney U-test tested respectively for parametric and non-parametric data. The independent tests for the two samples supported a claim that they represent the same underlying population of organizations.

A non-response bias was not evident. Testing for a non-response bias was amongst the mailed survey of 257 ConsultCo client organizations, as this survey had a known response rate of $16.75 \%$. Accordingly, we identified from the 36 responses of the mailed survey two groups of nine. These two groups are the first and last quartile of responses based on their returned mail date. The two response quartiles for the variables of hypotheses $\mathrm{H} 1$ and $\mathrm{H} 2$ had no significant differences. The conclusion is that the respondents from the ConsultCo client organizations contained no bias between the early and late responders, and there is no trend to suggest that the non-respondents had a bias regarding the tested variables.

The reflective measures for each variable covary with one another. This indicates internal reliability of the measures to reflect the same phenomenon (Petter et al., 2007). All process maturity measures that constitute POLINTCON displayed covariance when the 79 responses where plotted on a distribution chart.
The common movement for POLICY, INTELL and CONTRL had three inflexion points, where the first inflexion point was higher than the last on the maturity scale. The four frequency measures of D-OPTIONS also displayed common movement, with a high inflexion point in the first part of the frequency scale, followed by a longer tail. The five agreement measures of ITBENEFIT all had a high inflexion point in the second part of the agreement scale, preceded by a long tail.

\section{Data analysis}

When a variable has multiple measures, the measurement items must demonstrate reliability and validity. Convergent reliability is the extent that all the measurement items for a given variable have consistent values (Gefen et al., 2000). A Cronbach's alpha of 0.7 is a benchmark for convergent reliability. A second measure is composite reliability and a recommended benchmark is 0.70 (Hulland, 1999). That the PLS path modeling exceeded these two benchmarks indicated strong convergent reliability (Table 4).

For measurement item's reliability, the loading of the measurement item to its respective variable should be 0.7 or more (Hulland, 1999). Table 5 shows the loadings of the measurement items had sufficient reliability, after rounding to a single decimal place.

Discriminant validity is the extent to which measurement items of a given variable differ from measurement items of other variables in the same structural model (Hulland 1999). The root of the average variance extracted (AVE) for each variable is in the italicized diagonal of the correlation matrix (Table 6) all show adequate discriminant validity. Discri- 
Agility in Information Systems: Enabling Capabilities for the IT Function / Hobbs \& Scheepers

minant validity was only required of the firstorder variables in any hierarchical construct (Wetzels et al., 2009).

The 79 cases had no missing values and Kolmogorov-Smirnov tests suggested imperfect but significant data normality (Hobbs,
2010). The software used was SmartPLS version 2.0.M3 (Ringle et al., 2005). The PLS algorithm used measurement standardization for the different ordinal scales in the reflective measures and a centroid-weighting scheme.

\section{Table 5 - Measurement model and standardized loadings}

\begin{tabular}{|l|l|l|l|}
\hline \multicolumn{1}{|c|}{ First order variables } & Loading & Second order variables & Loading \\
\hline AGR24 $\leftarrow$ ITBENEFIT & 0.841 & & \\
\hline AGR25 $\leftarrow$ ITBENEFIT & 0.789 & & \\
\hline AGR26 $\leftarrow$ ITBENEFIT & 0.865 & & \\
\hline AGR27 $\leftarrow$ ITBENEFIT & 0.820 & & \\
\hline AGR28 $\leftarrow$ ITBENEFIT & 0.894 & & \\
\hline FRQ07 $\leftarrow$ D-OPTIONS & 0.860 & & \\
\hline FRQ08 $\leftarrow$ D-OPTIONS & 0.891 & & \\
\hline FRQ09 $\leftarrow$ D-OPTIONS & 0.898 & & \\
\hline FRQ10 $\leftarrow$ D-OPTIONS & 0.790 & & 0.858 \\
\hline MAT34 $\leftarrow$ INTELL & 0.890 & MAT34 $\leftarrow$ POLINTCON & 0.855 \\
\hline MAT35 $\leftarrow$ INTELL & 0.907 & MAT35 $\leftarrow$ POLINTCON & 0.877 \\
\hline MAT36 $\leftarrow$ INTELL & 0.863 & MAT36 $\leftarrow$ POLINTCON & 0.813 \\
\hline MAT37 $\leftarrow$ POLICY & 0.906 & MAT37 $\leftarrow$ POLINTCON & 0.826 \\
\hline MAT38 $\leftarrow$ POLICY & 0.893 & MAT38 $\leftarrow$ POLINTCON & 0.821 \\
\hline MAT39 $\leftarrow$ POLICY & 0.901 & MAT39 $\leftarrow$ POLINTCON & 0.765 \\
\hline MAT40 INTELL & 0.781 & MAT40 $\leftarrow$ POLINTCON & 0.822 \\
\hline MAT43 $\leftarrow$ INTELL & 0.846 & MAT43 $\leftarrow$ POLINTCON & 0.791 \\
\hline MAT44 $\leftarrow$ INTELL & 0.804 & MAT44 $\leftarrow$ POLINTCON & 0.825 \\
\hline MAT45 $\leftarrow$ CONTRL & 0.829 & MAT45 $\leftarrow$ POLINTCON & 0.723 \\
\hline MAT46 CONTRL & 0.899 & MAT46 $\leftarrow$ POLINTCON & 0.673 \\
\hline MAT47 $\leftarrow$ CONTRL & 0.868 & MAT47 $\leftarrow$ POLINTCON & \\
\hline
\end{tabular}

\begin{tabular}{|c|c|c|c|c|c|}
\hline & CONTRL & D-OPTIONS & INTELL & ITBENEFIT & POLICY \\
\hline CONTRL & 0.866 & & & & \\
\hline D-OPTIONS & 0.641 & 0.861 & & & \\
\hline INTELL & 0.781 & 0.722 & 0.851 & & \\
\hline ITBENEFIT & 0.615 & 0.607 & 0.644 & 0.843 & \\
\hline POLICY & 0.686 & 0.593 & 0.850 & 0.542 & 0.900 \\
\hline
\end{tabular}




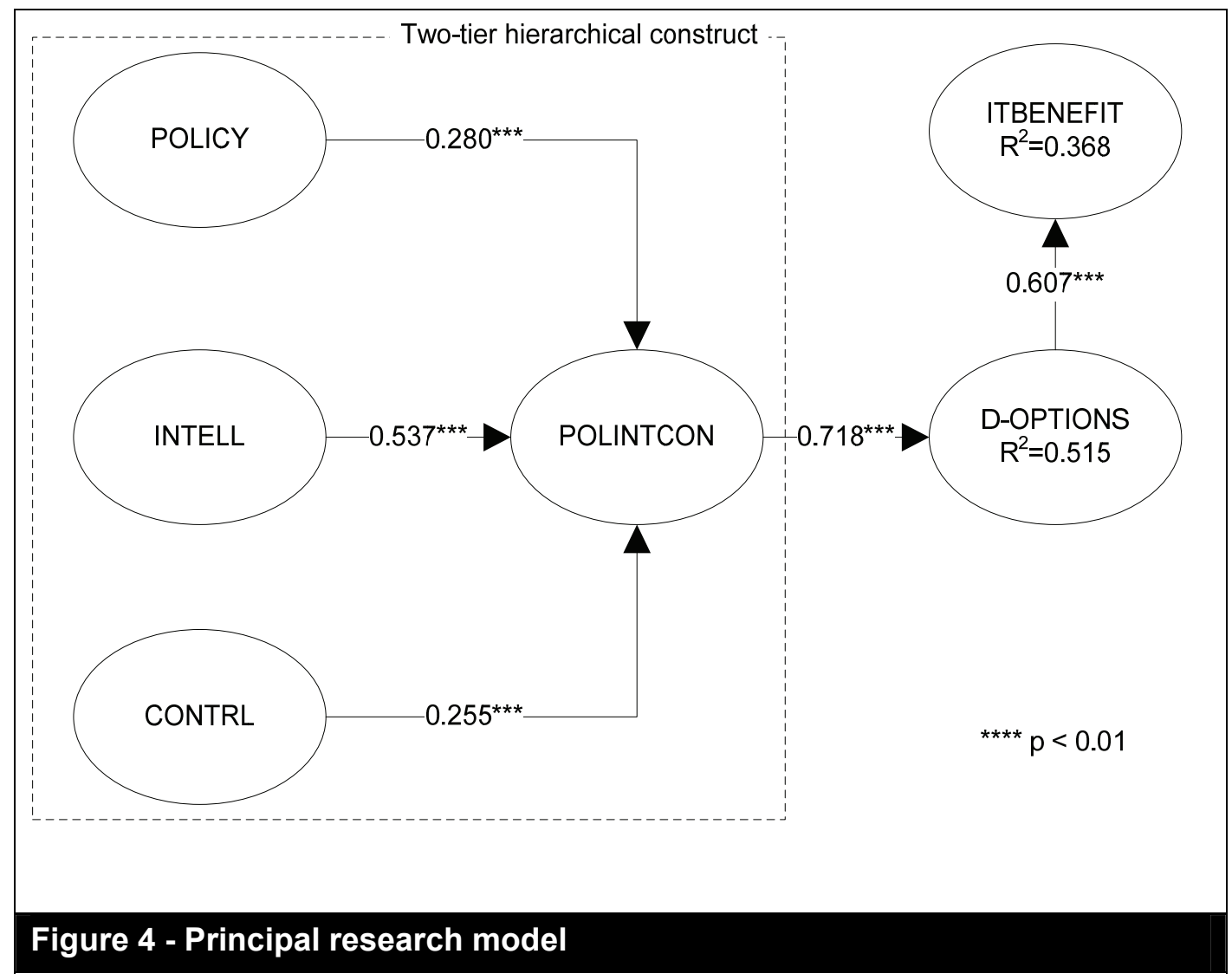

\section{Findings}

The primary purpose of the quantitative data analysis was theory testing. The use of PLS path modeling is valid for this purpose (Marcoulides and Saunders, 2006). All completed responses $(n=79)$ from the mailed and webbased surveys were utilized in the modeling to provide the maximum opportunity for falsification.

The PLS path modeling in Figure 4 showed a positive correlation between POLINTCON and D-OPTIONS $(\beta=0.718, t=13.554, p<0.01)$ and did not falsify the $\mathrm{H} 1$ hypothesis. Similarly, the positive correlation between $D$ OPTIONS and ITBENEFIT $(B=0.607$, $t=11.690, p<0.01$ ) did not falsify the $\mathrm{H} 2$ hypothesis. Significance testing used a bootstrap procedure with 2000 samples of the 79 responses. The two-tailed, t-values of measurement item weights and the variable correlations were all significant at $p<0.01$ for Type I errors.
The PLS path modeling achieved a statistical power in excess of 0.80 , considered by most researchers as acceptable to reject a false null hypothesis (Type II errors). The claim was based on the loadings of measurement items rounding to 0.7 or greater (Table 5 ) and path correlations between constructs were 0.6 or greater (Figure 4). These large effect sizes require a sample size of 23 to achieve a power of 0.80 , as determined in Marcoulides and Saunders (2006). The sample size of 79 used was more than sufficient to claim an acceptable level of statistical power.

Testing of hypotheses $\mathrm{H} 1 \mathrm{a}, \mathrm{H} 1 \mathrm{~b}$ and $\mathrm{H} 1 \mathrm{c}$ unbundled the POLINTCON construct into a two-order hierarchical construct. Wetzel et al. (2009) recommend for hierarchical constructs the repeated use of each measurement item in each order of the construct. Thus, the three reflective measures for POLICY, the six measures of INTELL and three measures of CONTRL, in the first-order of the hierarchical construct, were again linked as twelve reflec- 
Agility in Information Systems: Enabling Capabilities for the IT Function / Hobbs \& Scheepers

tive measures of the second-order for POLINTCON (Table 5). Wetzel et al. (2009) guide the deriving of the indirect effects of a first-order exogenous variable on an endogenous variable. From Figure 4, the indirect effects of the first-order exogenous variables on D-OPTIONS calculated as:

- POLICY $\rightarrow$ POLINTCON $(ß=0.280)$ and POLINTCON $\rightarrow$ D-OPTIONS $\quad(ß=0.718)$ having the product 0.201 ;

- INTELL $\rightarrow$ POLINTCON $(ß=0.537)$ and POLINTCON $\rightarrow$ D-OPTIONS $\quad(\quad=0.718)$ having the product 0.386 ;

- CONTRL $\rightarrow$ POLINTCON ( $(=0.255)$ and POLINTCON $\rightarrow$ D-OPTIONS $\quad(ß=0.718)$ having the product 0.183 .

The hierarchical construct reveals the relative contribution of POLICY, INTELL and CONTRL to enable agility in existing information systems. From the IS practice perspective, the IT function of a large organization should look first to the Strategy and Enterprise Architecture office, where Intelligence is typically housed, to see where more than half the capability for enabling agility is determined. Following that, attention can fall on the steering committees and application management offices, which respectively house Policy and Control, and share the remaining half of the agility capability.

\section{Improvement over existing prac- tice}

A purpose of this research was to consider both the IS theoretical and practical perspectives that inform the enablement of agility. We identified maturity objectives for the IT function based in existing practice and informed by cybernetic principles. PLS path modeling found the existing COBIT objectives linked the goal Creating IT agility (Table 7) had a weaker determination for agility outcomes (DOPTIONS, R2=0.379) than the research model that used POLINTCON as an exogenous variable (Figure 4, D-OPTIONS, $\mathrm{R} 2=0.515)$. Both models displayed high statistical power and significance, strong convergent reliability, strong discriminant validity and item reliability for each measurement.

Informed by the meta-system processes of the VSM and concepts from the IS literature, this research identified additional COBIT objectives and derived new objectives, which determined more than half of the variance of agility amongst the survey responses. This suggested the meta-level cybernetic theory, applied to the IT function, better correlates with reported agility outcomes than the existing COBIT objectives do on their own.

What are missing in the COBIT framework are objectives to create agility that relate to the Policy-Intelligence-Control structure of the IT function (POLINTCON). This research created three new objectives (Table 8) and recognized eight existing COBIT objectives (Table 9) not previously linked to agility. A research recommendation is future versions of industry 'best practices' that address IT agility include both sets of objectives.

One could argue that adding control objectives to the existing COBIT-based model was an obvious improvement. The questions then become whether the additional objectives are necessary and sufficient, and how can this be justified theoretically? Using the VSM in this research offers a pathway to answer these fundamental questions and points towards a more comprehensive and defensible theory on agility.

\section{Table 5 - Existing objectives linked to Creating IT agility}

\begin{tabular}{|l|l|}
\hline Define IT processes, organization \& relationships & $\mathrm{PO} 4$ \\
\hline To manage IT human resources & $\mathrm{PO} 7$ \\
\hline To acquire and maintain technology infrastructure & $\mathrm{Al} 3$ \\
\hline Integrity Management & $\mathrm{PO} 2.4$ \\
\hline
\end{tabular}


Table 6 - New objectives to be linked to Creating IT agility

Define high-level designs for forecasted business initiatives

Implement configurable software for forecasted business initiatives

Assess unexpected operational consequences to forecast business initiatives

Table 7 - Existing COBIT control objectives not yet linked to Creating IT agility

\begin{tabular}{|l|l|}
\hline IT policies management & $\mathrm{PO} 6.3$ \\
\hline Define the IT relationships & $\mathrm{PO} 4.15$ \\
\hline Define a strategic IT plan & $\mathrm{PO} 1.4$ \\
\hline Monitoring future trends and regulations & $\mathrm{PO} 3.3$ \\
\hline Technological direction planning & $\mathrm{PO} 3.1$ \\
\hline Acquire and maintain application software & $\mathrm{Al} 2$ \\
\hline Monitoring and reporting of service levels & $\mathrm{DS} 1.5$ \\
\hline Reporting and trend analysis & $\mathrm{DS} 8.5$ \\
\hline
\end{tabular}

\section{Generalization of findings}

We believe the research finding is transferable to other settings beyond the survey samples. Additional PLS path modeling used only data from the 34 client organizations of ConsultCo to determine transferability. This subset of data collected had fully identified respondents to measure their representativeness to a target population of large enterprises in OECD member countries.

The transferability modeling did not include the 35 international companies from Linkedln discussion group members, as the webbased survey was anonymous and the attributes of the respondents are unverifiable from the public knowledge of their organizations. Similarly, three responses from the mailed survey of ConsultCo clients were not included in the transferability profile. In one case, the respondent removed the identifier from the questionnaire; and in two cases, they were the second response from an organization. Further, the eight responses from the pilot of ConsultCo consultants were not included so not to over represent the IT consultancy.

The results of the PLS path modeling for transferability $(n=34)$ was comparable with that of the principal research modeling $(n=79)$. The positive path coefficient between POLINTCON and D-OPTIONS are consistent $(ß=0.734, \quad p<0.01$ cf. Figure $4, \quad=0.718$, $p<0.01)$. Similarly, the positive path coefficient between D-OPTIONS and ITBENEFIT are consistent between the two models $(ß=0.602, \quad p<0.01$ cf. Figure $4, \quad \beta=0.607$, $p<0.01)$. The transferability modeling displayed high statistical power and significance, strong convergent validity, adequate discriminant validity and item reliability for each measurement.

Consequently, the 33 client organizations were classified into Australian Bureau of Statistics' industry sectors, and compared against each sector's contribution to Australian GDP in 2005-2006 (Australian Bureau of Statistics, 2008). The incidence of industry sectors in the sample of ConsultCo client organizations was mostly comparable to the contribution of those sectors to the total Australian economy, within five percentage points. The exception was an over-representation of the electricity, gas and water supply, and an under-representation of the construction and wholesale trade sectors.

The sectoral composition of Australian industry is mostly representative of other OECD countries, with only the government, health, education and other personal services sector differing by more the five-percentage points from the USA. Our inference that the findings of this research are transferable to large en 
Table 8 - Correlations adjusted for CMV

\begin{tabular}{|c|c|c|c|}
\hline Independent variable & Dependent variable & Unadjusted correlation & Adjusted correlation \\
\hline POLINTCON & D-OPTIONS & 0.718 & 0.666 \\
\hline D-OPTIONS & ITBENEFIT & 0.607 & 0.534 \\
\hline
\end{tabular}

terprises was borne by the sample of the ConsultCo client organizations being representative of the population of Australian organizations, and that Australian organizations are representative of other OECD countries.

\section{Limitations}

As with most Likert-type survey research, it is possible that common method variance (CMV) inflated the correlation found among the variables. Malhotra et al (2006) recommend the marker variable technique for assessing CMV as effective for IS research. The questionnaire included an item that asked how frequently does your company "Have escalations or unresolved issues due to lack of, or insufficient responsibility for, assignments?" This measurement item met the post hoc analysis criteria for a marker variable by having the smallest positive correlation with an endogenous variable (Malhotra et al., 2006).

The marker variable had a correlation with $D$ OPTIONS of 0.156 . Table 10 shows the correlations between variables of hypotheses $\mathrm{H} 1$ and $\mathrm{H} 2$ adjusted by the CMV estimate. The adjusted correlations suggest that CMV may be present in the survey responses but only accounts for a small reduction from the uncorrected correlations. The adjusted t-values of the correlations remain significant at $p<$ 0.01 .

A second limitation might arise from the overrepresentation of the clients of ConsultCo when generalizing the findings to other organizations. It is arguable that those organizations that engage an IT consultancy may be less internally capable of agility, and therefore over-represents poor process maturity or poorly realized IT-dependent strategic benefits.

A research limitation was the reliance on COBIT as a representative industry frame- work for the IS practice perspective on agility. COBIT has widespread adoption (Ridley et al., 2004) and an explicit goal to Create IT agility (IT Governance Institute, 2007). The alternative frameworks of ITIL and TOGAF are not explicit in creating agility and less suitable as a practice perspective for this research.

\section{Conclusion}

This research contrasted the agility perspective from a widely used industry framework with research perspectives on agility in the IS literature. This research suggested Beer's Viable System Model was a useful meta-level theory to house agility elements from IS research literature, and apply VSM principles to identify the structure required of the IT function. By means of a survey of 70 organizations, this research confirmed that the metalevel theory better correlates with reported agility measures than existing practice measures do on their own. An agility-capability model was the product of this research (Figure 5).

The leftmost box of the agility-capability model contains the structure of the IT function necessary to produce agility activities. Informed by the VSM meta-system Policy sets the overall goals of the information systems, Intelligence looks outside the existing systems and to the future, and Control focuses on the existing systems now. A set of IT processes, drawn mostly from COBIT control objectives, reflect the agility capabilities of the IT functions.

The centre column of the agility-capability model has agility activities gleaned from the IS theoretical literature, and includes the concept of digital options. Digital options are rights to future IT configurations made by an initial IT investment without an obligation for full investment (Sambamurthy et al., 2003). 
IT function

- consists of IT personnel

- meta-system of the existing information systems

\section{Policy}

reflected by the maturity of the processes

to:

- Manage IT policies

- Define the IT relationships

- Define a strategic IT plan

Intelligence

reflected by the maturity of the processes

to:

- Monitor future trends \& regulations

- Assess unexpected operational consequences

- Plan technological direction

- Do feasibility studies and formulation of alternative courses of action

- Acquire \& maintain designs for forecasted business initiatives

- Implement configurable software for forecasted business initiatives

\section{Control}

reflected by the maturity of the processes to:

- Monitor service levels

- Reporting \& trend analysis

- Acquire \& maintain application software

Agility activities

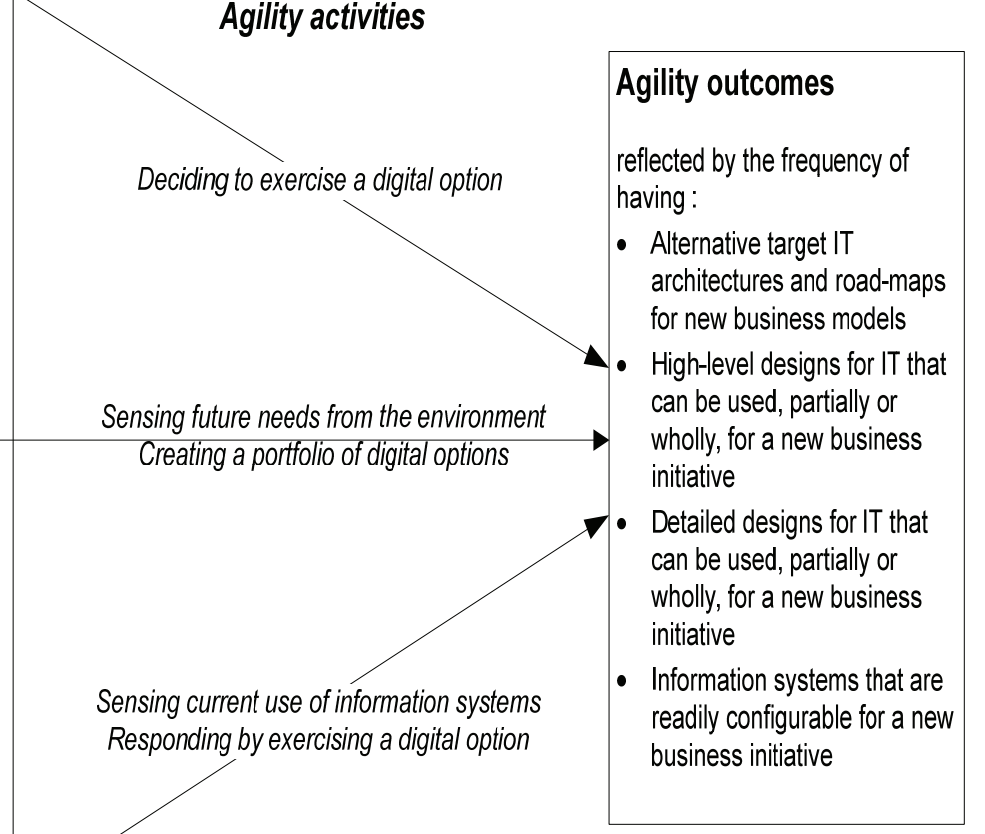

Figure 5 - The agility-capability model

The Policy, Intelligence and Control structure of the IT function links to the agility activities.

The rightmost box of agility-capability model of Figure 5 shows the outcomes from the agility activities. The occurrence of exercisable digital options reflects the agility outcomes. These events are prior initial IT investments for forecasted business initiatives completed to various stages in the systems development life cycle, and afford a head start to delivering an adaptation to existing information systems once a forecasted business initiative arrives. The initial IT investments is a head start on the full IT investment, and allows an agile adaptation faster than conventional planning cycles, where full IT investments commences when the request for a business initiative is received.

The agility-capability model of Figure 5 is theory that explains and predicts. The prescribed IT function subsystems are a large determinant of the agility outcomes (Figure 4, 
D-OPTIONS, R2=0.515). Intelligence, which is often associated with the strategy \& enterprise architecture office, contributes more than half of the IT function determination of agility. Policy and Control share the remaining determination of agility by the IT function, and are respectively associated with steering committees and application management offices.

The agility-capability model also addresses of the basic model for agility identified in existing IS research, which does not to extend to theories of explaining and predicting or theories of design and action. The model prescribes IT function activities to sense future needs from the environment, sense current use of information systems, create a portfolio of digital options and decide to exercise a digital option.

This research fills gaps identified in IS literature. Fink and Neumann (2007) suggest future research to identify the mechanisms underlying shared IT personnel and IT infrastructure capabilities that afford agility. The theory of explanation and prediction for agility in information systems, extended by this research, identifies the VSM as a plausible mechanism. Recognition of this IS research gap is echoed by Sambamurthy et al. (2007), who state the internal mechanisms for deploying and utilizing IT resources to enable organizational agility remains under-researched.

We demonstrated in this research that the IS theoretical and practice perspectives on agility are reconcilable through cybernetics. The cybernetic framework complemented the model of agility from the existing IS theoretical perspectives. The VSM application provided a testable theory of agility that explains and predicts (Gregor, 2006), which was missing from the IS theoretical perspectives, and required to inform IS practice to plan and action agility. Gartner Research (Plummer and McCoy, 2006) states enterprises must learn how to measure agility and make investments to improve their capability, and predicts best practices for agility will emerge through to 2011. A contribution of this research is to meet this IS practitioner need.

\section{Acknowledgements}

The authors wish to acknowledge Oakton, an Australian technology and business consulting company, as the industry partner of this research. We particularly thank James Watson of Oakton for his continued support as the demands for this research evolved. This research was supported under Australian Research Council's Linkage Projects funding scheme (project LP0561936). The views expressed herein are those of the authors and are not necessarily those of the Australian Research Council. George Hobbs is especially thankful for the encouragement given during his doctoral candidature by his wife, Donna.

\section{References}

Agarwal, R. and V. Sambamurthy (2002) "Principles and models for organizing the IT function," MIS Quarterly Executive (1) 1, pp. 1-16.

Andrade, L. F. and J. L. Fladeiro (2002) "Agility through coordination," Information Systems (27) 6, pp. 411-424.

Ashby, W. R. (1956) An Introduction to Cybernetics. London: Chapman \& Hall.

Australian Bureau of Statistics. (2008) 2008 Australia at a glance. Commonwealth of Australia ISSN 1031-0541.

Beer, S. (1979) The Heart of Enterprise. Chichester: Wiley.

Beer, S. (1984) "The Viable System Model: Its Provenance, Development, Methodology and Pathology," The Journal of the Operational Research Society (35) 1, pp. 7-25.

Berente, N. (2005) ERP and Innovation in Schumpeterian Market Dynamics, in AMCIS 2005 Proceedings.

Börjesson, A., F. Martinsson, and M. Timmeras (2006) "Agile improvement practices in software organizations," European Journal of Information Systems (15) 2, pp. 169-182. 
Conant, R. C. and W. R. Ashby (1970) "Every good regulator of a system must be a model of that system," International Journal of Systems Science (1) 2, pp. 89-97.

Cornford, T., W. Venters, and Y. Zheng (2007) Agility, Improvisation, or Enacted Emergence, in ICIS 2007 Proceedings.

Desouza, K. C. (2006) Agile Information Systems: Conceptualization, Construction, and Management. Oxford: Butterworth Heinemann.

Fink, L. and S. Neumann (2007) "Gaining Agility through IT Personnel Capabilities: The Mediating Role of IT Infrastructure Capabilities," Journal of the Association for Information Systems (8) 8, pp. 440-462.

Fitzgerald, B., G. Hartnett, and K. Conboy (2006) "Customising agile methods to software practices at Intel Shannon," European Journal of Information Systems (15) 2, pp. 200-213.

Galliers, R. D. (2006) Strategizing for Agility: Confronting Information Systems Inflexibility, in K. C. Desouza (Ed.) Agile Information Systems: Conceptualization, Construction, and Management, Oxford: Butterworth Heinemann.

Gefen, D., D. W. Straub, and M.-C. Boudreau (2000) "Structural Equation Modeling and Regression: Guidelines for Research Practice," Communications of the Association for Information Systems (4) 7, pp. 1-79.

Goethals, F. G., M. Snoeck, W. Lemahieu, and J. Vandenbulcke (2006) "Management and enterprise architecture click: The FAD(E)E Framework," Information Systems Frontiers (8) 2, pp. 67-79.

Gregor, S. (2006) "The nature of theory in information systems," MIS Quarterly (30) 3, pp. 611-642.

Haslett, T. and R. Sarah (2006) "Using the viable systems model to structure a system dynamics mapping and modeling project for the Australian Taxation Office," Systemic Practice and Action Research (19) 3, pp. 273-290.

Henderson, J. and N. Venkatraman (1993) "Strategic Alignment: Leveraging Information Technology for Transforming Organizations," IBM Systems Journal (32) 1, pp. 4-16.

Hobbs, G. A. (2010) Enabling agility in existing information systems: A capability structure for the IT function. PhD thesis, The University of Melbourne.

Holmqvist, M. and K. Pessi (2006) "Agility through scenario development and continuous implementation: a global aftermarket logistics case," European Journal of Information Systems (15) 2, pp. 146-158.

Hulland, J. (1999) "Use of Partial Least Squares (PLS) in Strategic Management Research: A Review of Four Recent Studies," Strategic Management Journal (20) 2, pp. 195-204.

Humphrey, W. S. (1987) Characterizing the software process: a maturity framework. Software Engineering Institute Carnegie Mellon University CMU/SEI87-TR-11.

IT Governance Institute. (2007) COBIT 4.1: Framework, Control Objectives, Management Guidelines, Maturity Models. IT Governance Institute.

Linkedln Corporation (2008) "Linkedln Groups," Linkedln Corporation, http://www.linkedin.com/ (13 January, 2008).

Luftman, J. and E. McLean (2004) "Key Issues for IT Executives," MIS Quarterly Executive (3) 2, pp. 89-104.

Lyytinen, K. and G. M. Rose (2006) "Information system development agility as organizational learning," European Journal of Information Systems (15) 2, pp. 183-199. 
Agility in Information Systems: Enabling Capabilities for the IT Function / Hobbs \& Scheepers

Malhotra, N. K., S. S. Kim, and A. Patil (2006) "Common Method Variance in IS Research: A Comparison of Alternative Approaches and a Reanalysis of Past Research," Management Science (52) 12, pp. 1865-1883.

Marcoulides, G. A. and C. Saunders (2006) "PLS: A Silver Bullet?," MIS Quarterly (30) 2, pp. iii-ix.

Markus, M. (2000) "Paradigm Shifts-EBusiness and Business/Systems Integration," Communications of the Association for Information Systems (4) 10, pp. 1-44.

Mathiassen, L. and J. Pries-Heje (2006) "Business agility and diffusion of information technology," European Journal of Information Systems (15) 2, pp. 116-119.

Mirani, R. and A. L. Lederer (1998) "An Instrument for Assessing the Organizational Benefits of IS Projects," Decision Sciences (29) 4, pp. 803-838.

Newman, D. and D. Logan. (2006a) Achieving Agility: How Enterprise Information Management Overcomes Information Silos. Gartner Research G00137817.

Newman, D. and D. Logan. (2006b) Achieving Agility: How Enterprise Information Management Overcomes Information Silos. Gartner G00137817.

Otto, B., K. Wende, A. Schmidt, and P. OsI (2007) Towards a Framework for Corporate Data Quality Management, in ACIS 2007 Proceedings. Toowoomba.

Overby, E., A. Bharadwaj, and V. Sambamurthy (2006) "Enterprise agility and the enabling role of information technology," European Journal of Information Systems (15) 2, pp. 120-131.

Patten, K., B. Whitworth, J. Fjermestad, and E. Mahinda. (2005) Leading IT flexibility: anticipation, agility and adaptability. Eleventh Americas Conference on Information Systems, Omaha, Nebraska, 2005, pp. 11-14.
Peppard, J. and J. Ward (2004) "Beyond strategic information systems: towards an IS capability," Journal of Strategic Information Systems (13) 2, pp. 167194.

Petter, S., D. Straub, and A. Rai (2007) "Specifying Formative Constructs in Information Systems Research," MIS Quarterly (31) 4, pp. 623-656.

Plummer, D. C. and D. W. McCoy. (2006) Achieving Agility: Defining Agility in an IT Context. Gartner Research G00137819.

Raschke, R. L. and J. S. David (2005) Business Process Agility, in AMCIS 2005 Proceedings.

Ridley, G., J. Young, and P. Carroll. (2004) COBIT and its utilization: a framework from the literature. 37th Annual Hawaii International Conference on System Sciences, 2004, pp. 8.

Ringle, C. M., S. Wende, and A. Will (2005) SmartPLS, 2.0 (beta) edition. Hamburg, Germany: University of Hamburg.

Sambamurthy, V., A. Bharadwaj, and V. Grover (2003) "Shaping Agility through Digital Options: Reconceptualizing the Role of Information Technology in Contemporary Firms," MIS Quarterly (27) 2, pp. 237-263.

Sambamurthy, V., K.-K. Wei, K. Lim, and D. Lee (2007) IT-Enabled Organizational Agility and Firms' Sustainable Competitive Advantage, in ICIS 2007 Proceedings.

Schwaninger, M. (2006) "Design for viable organizations: the diagnostic power of the viable system model," Kybernetes (35) 7-8, pp. 955-966.

Seo, D., K. Desouza, and J. Erickson (2006) Opening up the Black-Box: Information Systems and Organizational Agility, in AMCIS 2006 Proceedings.

Seo, D. B. and A. I. La Paz (2008) "Exploring the dark side of IS in achieving orga- 
nizational agility," Communications of the ACM (51) 11, pp. 136-139.

Shaw, D., B. Snowdon, C. Holland, P. Kawalek et al. (2004) "The viable systems model applied to a smart network: the case of the UK electricity market," Journal of Information Technology (19) 4, pp. 270-280.

Sledgianowski, D., J. Luftman, and R. Reilly (2006) "Development and Validation of an Instrument to Measure Maturity of IT Business Strategic Alignment Mechanisms," Information Resources Management Journal (19) 3, pp. 3-18.

Umar, A. (2005) "IT infrastructure to enable next generation enterprises," Information Systems Frontiers (7) 3, pp. $217-$ 256.

Walker, J. (2001) "The Viable Systems Model: A guide for co-operatives and federations,"

www.esrad.org.uk/resources/vsmg_2.

2/pdf/vsmg_2_2.pdf (1 November, 2006).

Weill, P. (2004) "Don't Just Lead, Govern: How Top-Performing Firms Govern IT," MIS Quarterly Executive (3) 1, pp. 1-17.

Weill, P., M. Subramani, and M. Broadbent (2002) "Building IT Infrastructure for Strategic Agility," MIT Sloan Management Review (44) 1, pp. 57-65.

Wetzels, M., G. Odekerken-Schroder, and C. van Oppen (2009) "Using PLS Path Modeling for Assessing Hierarchical Construct Models: Guidelines and Empirical Illustration," MIS Quarterly (33) 1, pp. 177-195.

Zhao, J., M. Tanniru, and L.-J. Zhang (2007) "Services computing as the foundation of enterprise agility: Overview of recent advances and introduction to the special issue," Information Systems Frontiers (9) 1, pp. 1-8.

\section{About Authors}

Dr. George Hobbs has a Masters of Information Systems and a PhD awarded by the University of Melbourne in 2010. His research interests include the role of the IT function in enabling agility in information systems and cybernetics. He has reviewed for the Australasian Conference on Information Systems and the Journal of Information Technology, and coordinated the Organisational and Social Aspects of Information Systems research group at the University of Melbourne. George has been an IT professional for over 20 years, with placements at Telstra, EDS Australia, Accenture and the National Australia Bank. His current position is with NBN Co, the government enterprise charged with networking Australian homes with fibre-to-the-premises connection.

Dr. Rens Scheepers is an Associate Professor of Information Systems at the University of Melbourne. His research interest is in the implementation of, and business value derived from, complex business systems. He has a Masters of Business Administration from the University of Pretoria and a PhD from Aalborg University awarded in 1999. Rens has been an Associate Editor for the Journal of Information Technology and for the Journal of Strategic Information Systems. He has served as the Deputy Head of the Department of Information Systems at the University of Melbourne and is currently an executive committee member of the Institute for a Broadband-enabled Society (IBES). Rens has accepted the Chair of Information Systems at Deakin University. 